\title{
The Comprehensive Evaluation Research of Automated Charging Station's Lightning Protection Design in Airport
}

\author{
Baocheng Wang, Guyong Han, Lin Zhu \\ Xuzhou Air Force College, Xuzhou, China \\ Email: xzkjxywangbaocheng@163.com
}

Received December 2013

\begin{abstract}
In order to inspect the good and reliability of automated charging station's lightning protection design in airport, we set the comprehensive evaluation mathematical model of automated charging station in the airport, through the method of second order fuzzy comprehensive evaluation and evaluate the automated charging station's lightning protection design comprehensively by using the assessment data of expert database.
\end{abstract}

\section{Keywords}

Automated Charging Station in Airport; Second Order Fuzzy Comprehensive Evaluation; Comprehensive Evaluation of Lightning Protection Design

\section{The Analysis of the Comprehensive Evaluation Index System about the Lightning Protection System in Automatic Charging Station}

Index is the specific concept and value of the overall phenomena's reflection. Generally, the overall phenomena need several indexes to be reflected. And the index system is made of these related indexes. Index system reflects the digital relationship of the overall phenomena. It helps us to understand the relationship and development process of the content of technology economy comprehensively and deeply. Index system can't be set as we want and it has some principles. In this way, the index system that we set can be more reasonable and persuasive. Generally, index system should follow the following principles: system overall principles, scientific rigor principles, concise accurate principles, highlight the key principles, stable comparable principles and flexible feasibility principles. The overall level of automated charging station's comprehensive lightning protection design in airport involves many factors, such as resources equipment technology and human. So when evaluate the feasibility of automated charging station's comprehensive lightning protection design, we should set a quantitative index system according to the characteristics of lightning protection system and different levels and angles. In this way, the evaluation can be comprehensive and scientific.

According to the evaluation of the index system such as integrity, mathematical and no redundancy, and the practical characteristics of automated charging station's lightning protection design system, we develop the pri- 
mary index collection and determine various index rating criteria. We got the evaluation index system through analysis, as Figure 1 shows [1].

\section{The Analysis of the Fuzzy Comprehensive Evaluation Method}

The fuzzy comprehensive evaluation method is based on the fuzzy mathematics and applies the principle of fuzzy synthesis. It can quantitate the factors which are not easy to quantitate and have fuzzy boundary. It is a method of evaluating comprehensively. The fuzzy comprehensive evaluation method quantitates the fuzzy indexes that reflect the things which are evaluated, by structuring level fuzzy subsets and then, it synthesizes the indexes by using the principle of fuzzy transform. This method can considerate the subjective and objective factors and it is scientific intuitive and easy to operate.

A. Fuzzy Statistical Experiment

$r_{i j k}$ means the membership that the sub-factor

$u_{i j}$ belongs to level $v_{k}$.

$r_{i j k}$ is the ratio of the experts who vote for each sub-factor $u_{i j}$ on level $v_{k}$, to all of the experts who are tested. For every sub-factor $u_{i j}$, the statistical results can be expressed as:

$$
R_{i}=\left(\begin{array}{c}
R_{i 1} \\
R_{i 2} \\
\vdots \\
R_{i m}
\end{array}\right)=\left(\begin{array}{cccc}
r_{i 11} & r_{i 12} & r_{i 13} & r_{i 14} \\
r_{i 21} & r_{i 22} & r_{i 23} & r_{i 24} \\
\vdots & \ldots & \ldots & \ldots \\
r_{i m 1} & r_{i m 2} & r_{i m 3} & r_{i m 4}
\end{array}\right)
$$

In the expression, $R_{i}$ is the fuzzy matrix of $\left[u_{i}, V\right]$, and it is called evaluation matrix. Every line of the expression meets the normalization condition which is $\sum_{k=1}^{4} r_{i j k}=1$.

For every factor, the evaluation matrix must be ascertained through the first power fuzzy statistics.

\section{B. First Order Fuzzy Comprehensive Evaluation}

The first order evaluation $\mathrm{B}$ is $B_{i}=A_{i} \cdot R_{i}=\left(b_{i 1}, b_{i 2}, b_{i 3}, b_{i 4}\right)$. In this expression, $b_{i k}=\sum_{j=1}^{m} a_{i j} \cdot r_{i j k}$ and $b_{k}$ means the membership that the factor $u_{i}$ belong to level $v_{i} . B_{i}$ is the fuzzy subset of $V$. For each factor in this research, we get:

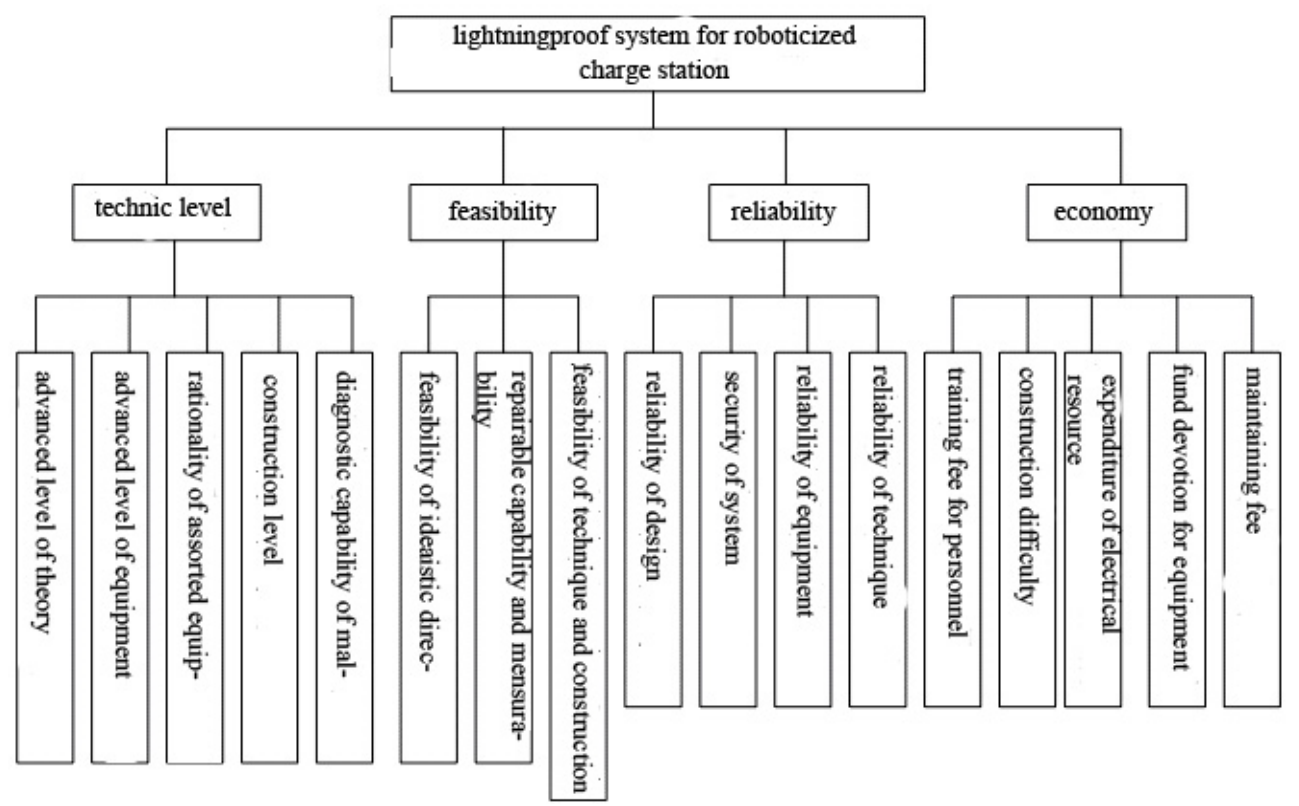

Figure 1. The evaluation index system of automated charging station's lightning protection system. 


$$
R=\left(\begin{array}{l}
B_{1} \\
B_{2} \\
B_{3} \\
B_{4}
\end{array}\right)=\left(\begin{array}{llll}
b_{11} & b_{12} & b_{13} & b_{14} \\
b_{21} & b_{22} & b_{23} & b_{24} \\
b_{31} & b_{32} & b_{33} & b_{34} \\
b_{41} & b_{42} & b_{43} & b_{44}
\end{array}\right)
$$

In this expression, $R$ is the fuzzy matrix of $[U, V]$.

C. Second Order Fuzzy Comprehensive Evaluation

The second order evaluation $\mathrm{B}$ is $B=A \cdot R=\left(b_{1}, b_{2}, b_{3}, b_{4}\right)$ and in this expression, $b_{k}=\sum_{i=1}^{4} a_{i} \cdot b_{i k}$ and $b_{k}$ is evaluation object and the membership that $U$ belong to level $v_{i} . B$ is the fuzzy subset of $V$ and the result vector of fuzzy comprehensive evaluation.

D. Comprehensive Evaluation Result

According to the principle of maximum membership degree or the transform $C=B \cdot V^{T}$, we can get the evaluation result $C$. We can analyze the evaluation result through the evaluation score $C$.

\section{The Design about Lightning Protection of the Fuzzy Comprehensive Evaluation in Automatic Charging Station}

Now, we evaluate the lightning protection design comprehensively through the method of second order fuzzy comprehensive evaluation [2]. We do statistics of the index's evaluation result which is evaluated by the experts. We get the relative weight and membership of each index by calculating, as Chart 1 shows.

Chart 1. The data chart of the fuzzy comprehensive evaluation of automated charging station's lightning protection scheme.

\begin{tabular}{|c|c|c|c|c|}
\hline \multicolumn{2}{|c|}{ The first index level } & \multicolumn{3}{|c|}{ The second index level } \\
\hline Factor & Weight & Sub-factor & Weight & Membership rij \\
\hline \multirow{5}{*}{$\begin{array}{c}\text { The technology } \\
\text { level }\end{array}$} & \multirow{5}{*}{0.25} & The advanced theory & 0.15 & $(0.3,0.4,0.3,0)$ \\
\hline & & The advanced equipment & 0.2 & $(0.4,0.3,0.3,0)$ \\
\hline & & $\begin{array}{l}\text { The reasonable equipment } \\
\text { cooperation }\end{array}$ & 0.3 & $(0.2,0.3,0.4,0.1)$ \\
\hline & & The construction level & 0.15 & $(0.25,0.4,0.35,0)$ \\
\hline & & The ability of fault diagnosis & 0.2 & $(0,0.3,0.4,0.3)$ \\
\hline \multirow{3}{*}{ Feasibility } & \multirow{3}{*}{0.2} & $\begin{array}{l}\text { The feasibility of guiding } \\
\text { ideology }\end{array}$ & 0.4 & $(0.2,0.4,0.4,0)$ \\
\hline & & $\begin{array}{l}\text { The maintaimability and } \\
\text { testability }\end{array}$ & 0.2 & $(0,0.3,0.5,0.2)$ \\
\hline & & $\begin{array}{l}\text { The feasibility of technology } \\
\text { and construction }\end{array}$ & 0.4 & $(0.2,0.3,0.5,0)$ \\
\hline \multirow{4}{*}{ Reliability } & \multirow{4}{*}{0.2} & The reliability of design & 0.3 & $(0.3,0.4,0.3,0)$ \\
\hline & & The safety of system & 0.3 & $(0.6,0.2,0.2,0)$ \\
\hline & & The reliability of equipment & 0.2 & $(0.2,0.4,0.3,0.1)$ \\
\hline & & The reliability of technology & 0.2 & $(0.2,0.5,0.3,0)$ \\
\hline \multirow{5}{*}{ Economy } & \multirow{5}{*}{0.35} & The personnel training feet & 0.1 & $(0.5,0.5,0,0)$ \\
\hline & & The construction difficulty? & 0.2 & $(0.4,0.3,0.3,0)$ \\
\hline & & The consumption of power & 0.1 & $(0.7,0.2,0.1,0)$ \\
\hline & & The investment in equipment & 0.4 & $(0.6,0.3,0.1,0)$ \\
\hline & & The maintenance fee & 0.2 & $(0.8,0.1,0.1,0)$ \\
\hline
\end{tabular}


According to the weight in Chart 1, we know:

$$
\begin{aligned}
& A=(0.25,0.2,0.2,0.35) \\
& A_{1}=(0.15,0.2,0.3,0.15,0.2) \\
& A_{2}=(0.4,0.2,0.4) \\
& A_{3}=(0.3,0.3,0.2,0.2) \\
& A_{4}=(0.1,0.2,0.1,0.4,0.2) \\
& R_{1}=\left(\begin{array}{cccc}
0.3 & 0.4 & 0.3 & 0 \\
0.4 & 0.3 & 0.3 & 0 \\
0.2 & 0.3 & 0.4 & 0.1 \\
0.25 & 0.4 & 0.35 & 0 \\
0 & 0.3 & 0.4 & 0.3
\end{array}\right) \\
& R_{2}=\left(\begin{array}{cccc}
0.2 & 0.4 & 0.4 & 0 \\
0 & 0.3 & 0.5 & 0.2 \\
0.2 & 0.3 & 0.5 & 0
\end{array}\right) \\
& R_{3}=\left(\begin{array}{cccc}
0.3 & 0.4 & 0.3 & 0 \\
0.6 & 0.2 & 0.2 & 0 \\
0.2 & 0.4 & 0.3 & 0.1 \\
0.2 & 0.5 & 0.3 & 0
\end{array}\right) \\
& R_{4}=\left(\begin{array}{cccc}
0.5 & 0.5 & 0 & 0 \\
0.4 & 0.3 & 0.3 & 0 \\
0.7 & 0.2 & 0.1 & 0 \\
0.6 & 0.3 & 0.1 & 0 \\
0.8 & 0.1 & 0.1 & 0
\end{array}\right)
\end{aligned}
$$

Then according to Formula 5-21, we get the result of first order fuzzy comprehensive evaluation:

$$
\begin{gathered}
B_{1}=A_{1} \cdot R_{1}=(0.2225,0.33,0.3575,0.09) \\
B_{2}=A_{2} \cdot R_{2}=(0.16,0.34,0.46,0.04) \\
B_{3}=A_{3} \cdot R_{3}=(0.35,0.36,0.27,0.02) \\
B_{4}=A_{4} \cdot R_{4}=(0.6,0.27,0.13,0)
\end{gathered}
$$

According to Formula 5-22, we get the first order comprehensive evaluation matrix:

$$
R=\left(\begin{array}{l}
B_{1} \\
B_{2} \\
B_{3} \\
B_{4}
\end{array}\right)=\left(\begin{array}{cccc}
0.2225 & 0.33 & 0.3575 & 0.09 \\
0.16 & 0.34 & 0.46 & 0.04 \\
0.35 & 0.36 & 0.27 & 0.02 \\
0.6 & 0.27 & 0.13 & 0
\end{array}\right)
$$

So, according to Formula 5-23, we get the second order evaluation $B$ :

$$
\begin{aligned}
& B=A \cdot R=(0.25,0.2,0.2,0.35)\left(\begin{array}{cccc}
0.2225 & 0.33 & 0.3575 & 0.09 \\
0.16 & 0.34 & 0.46 & 0.04 \\
0.35 & 0.36 & 0.27 & 0.02 \\
0.6 & 0.27 & 0.13 & 0
\end{array}\right) \\
& =(0.367625,0.317,0.280875,0.0345)
\end{aligned}
$$


If we set that $V=(0.9,0.7,0.5,0.4)$, according to the formula $C=B \cdot V^{T} \quad$ [3], we can calculate the eventual evaluation result:

$$
\begin{gathered}
C_{1}=B_{1} \cdot V^{T}=0.646 \\
C_{3}=B_{3} \cdot V^{T}=0.71 \\
C_{4}=B_{4} \cdot V^{T}=0.794 \\
C=B \cdot V^{T}=0.707
\end{gathered}
$$

So, in this scheme, the score of the technology level is 0.646 , the score of the feasibility is 0.628 , the score of the reliability is 0.71 , the score of the economy is 0.794 and the score of the overall scheme is 0.707 .

\section{The Evaluation Result Analysis of the Lightning Protection Design in Automatic Charging Station}

From the result, we can conclude that in the aspect of index weight, economy is dominant and the second is technology level. The weight of feasibility is as the same as reliability and their proportion is small. And the aspects of reasonable equipment cooperation, the feasibility of guiding ideology, the feasibility of technology and construction, the safety of system, the reliability of equipment and the investment in equipment and so on play main role.

We can see from the result that the score of the economy is 0.794 , the score of the reliability is 0.71 , and the level is good. The system has good economy mainly because the automated charging station's lightning protection design adopts the optimization scheme of the lightning protection equipment. By using the modern lightning protection technology, the usage of the lightning protection equipment can be lessened efficiently at the premise of guaranteeing lightning protection effect, so the later investment in lightning protection equipment can be lessened. The score of the feasibility is 0.628 and the score of the technology level is 0.646 and the levels of them are all medium. The score of the overall scheme is 0.707 and the level is good. The result reflects that this scheme is reliable, economic and efficient. We can also know from the result that this lightning protection design can have better protection effect but need more advanced technology and lightning protection equipment and in the condition of limited budget, the investment should be lessened. More scientific management and lightning protection and maintenance personnel with High business quality are also needed.

\section{References}

[1] Li, J.L., et al. (2009) The Technology of Modern Lightning Protection. China Water Conservancy and Hydropower Press, Beijing.

[2] Rao, X.R., Sun, Y.G., Qian, C.F. and Meng, X.X. (2007) Recognize Lightning Damage Discusses Lightning Protection Measures. The Military Meteorological Hydrology, 2.

[3] Wang, E.T., Zhu, X.P. and Zhang, J.L. (2007) Lightning Protection Technology New Trends and Radar Lightning Protection Countermeasures. Equipment Technology, 2, 56. 